\title{
Aggressive Waves in the Lemon-Clawed Fiddler Crab (Uca perplexa): A Regional "Dialect" in Fiji
}

\author{
Judith S. Weis ${ }^{1}$ and Peddrick Weis ${ }^{1,2}$ \\ ${ }^{1}$ Department of Biological Science, Rutgers University, Newark, NJ 07102, USA \\ ${ }^{2}$ Department of Radiology, UMDNJ-New Jersey Medical School, Newark, NJ 07101-1709, USA \\ Correspondence should be addressed to Peddrick Weis; pw203@umdnj.edu
}

Received 8 April 2013; Accepted 8 May 2013

Academic Editors: P. De los Ríos Escalante, R. Rico-Martinez, and P. K. S. Shin

Copyright (C) 2013 J. S. Weis and P. Weis. This is an open access article distributed under the Creative Commons Attribution License, which permits unrestricted use, distribution, and reproduction in any medium, provided the original work is properly cited.

\begin{abstract}
A population of the lemon-clawed fiddler crab (U. perplexa) in Fiji (island of Vanua Levu) was studied for types of communication (i.e., signaling via waving the male's larger claw). Two types of signals were observed. In addition to the expected territorial display of a large and complex vertical wave that conveys its message over a typical distance of 10-40 cm (with large males signaling to other large males over the greatest distance), a short, rapid, and horizontal wave was typically directed over a much shorter distance, rarely exceeding $10 \mathrm{~cm}$. This latter wave type, seemingly of an aggressive nature, differs from the vertically directed aggressive signal observed in an Australian population of this species and thus appears to be a regional "dialect" for this mode of communication.
\end{abstract}

\section{Introduction}

Animal communication signals are crucial to many species, as they may convey information to conspecifics about the identity, location, and motivation of the sender. This information is often valuable for reproductive success or survival. In the genus Uca (fiddler crabs), the male's enlarged claw is waved in order to attract females for mating, although it may also be used in territorial and agonistic displays and may be exhibited in the absence of a target. Different species have different patterns of claw waving $[1,2]$, helping females to find conspecific males $[3,4]$. Waves have been classified as "vertical" and "lateral" [1]. Vertical waves are described as simple lifts of the claw with little horizontal movement, while lateral waves include complicated lateral components (extending and flexing), in addition to vertical components, generally accompanied by walking leg and body movements. Since waving can have two very different functions, as a signal for mating or for conflict, the purpose of a given waving signal may be uncertain and confusing to both crustacean and human observers.

The courtship waving pattern of the lemon-clawed fiddler crab (U. perplexa) in Japan and Australia has been described
[1,5-7]. The typical wave, which has been termed a "lateral" wave, involves extending the claw, then raising it, and then lowering it rapidly to the resting position, taking 1-1.5 seconds. At the same time, the minor claw and front walking legs are also raised and lowered along with the major claw. This is a conspicuous signal that can be detected at a considerable distance, and it has been associated with courtship $[1,5,8,9]$.

How et al. [6] described a second, totally different, type of wave in Australian U. perplexa, a vertical wave in which the claw is raised and lowered very rapidly without extending; each wave is about 0.2 seconds and can be repeated in a rapid series. These simple waves had much less elevation, were not accompanied by leg movements, and would be observable only by nearby crabs. These waves were used in territorial interactions as well as courtship, and were elicited by male wanderers during agonistic interactions and female wanderers during close range courtship. Crane [1] stated that rapid vertical motions with a flexed claw are made only during high intensity threat.

In this paper, we describe a different, previously undescribed, type of wave in a population of U. perplexa in Fiji and its relation to distance between identity and relative sizes of individuals. 


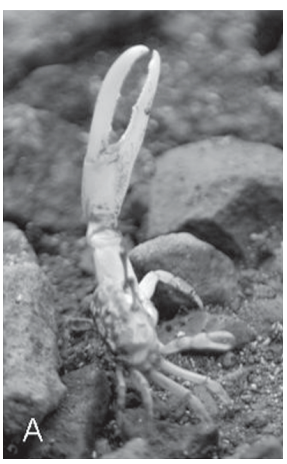

(a)

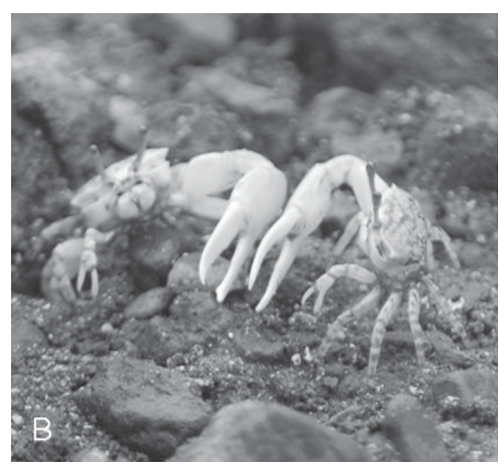

(b)
Figure 1: Uca perplexa exhibiting (a) a vertical (regular) wave, shown here at top of maneuver and (b) a shoving match that began with rapid horizontal waves (RHW).

\section{Methods}

Observations were made in December 2009 and January 2010 on a mud flat on the south shore of the Fijian island of Vanua Levu, in the Koro Sun Bay, $13.5 \mathrm{~km}$ by road east of the town of Savusavu $\left(16^{\circ} 47^{\prime} 51^{\prime \prime} \mathrm{S} \times 179^{\circ} 24^{\prime} 44^{\prime \prime} \mathrm{E}\right)$. At this location, a large colony of Uca perplexa was adjacent to a colony of $U$. vocans and a few individuals of $U$. tetragonon. Field observations were done by two experienced individuals who used close-focusing binoculars to scan the colony. Initial observations indicated that two types of waves took place, so both were recorded. Whenever either type of wave was observed, the focal individual was identified as either a small $(<10 \mathrm{~mm})$ or a large male (maximum carapace width for this species at this location being $\sim 14 \mathrm{~mm}$ ). The crab being waved at (target of the wave) was indicated (large or small male $U$. perplexa, female U. perplexa, U. tetragonon, or $U$. vocans), whenever the recipient was obvious, and the distance between the two crabs was estimated (rulers were placed on the mud flat for reference). When it was not clear who the receiver was, it was so indicated, and no distance was noted. Initial observations examined both types of waves to see which were performed more frequently and by whom. Later observations focused exclusively on the performers and targets of the quick/repeated horizontal wave. Digital imaging involved both still and brief video photography.

Statistical analysis involved Kruskal-Wallis (K-W) oneway analysis of variance. (Nonparametric analysis was required because of the unequal distribution of data.)

\section{Results and Discussion}

Two very different types of waves were noted. The typical wave, described by Crane [1] and How et al. [6] and termed a "lateral" wave, involves extending the claw horizontally, raising it, and then lowering it down rapidly to the resting position over 1.0-1.5 seconds; simultaneously, the small claw is also raised and the crab rises up on its front pair of walking legs (see Figure 1(a)). For reasons that will be clear, we prefer to call this a "regular" wave rather than a "lateral" wave, since it involves a considerable vertical component. Regular waves were performed somewhat more by large than small males and were addressed to both males and females. However, they were directed toward other males at a far greater frequency than to females. This may be due, in part, to the greater number of males out on the surface. Large males waving to other large males did so at the greatest distance compared to the other combinations of wavers and receivers, illustrated in Figure 2(a) $(\mathrm{K}-\mathrm{W}$ statistic $=15.4, P=0.009)$.

How et al. [6] also described a second wave type, a vertical wave, in which the claw is raised and lowered very rapidly without extending; each wave is about 0.2 seconds. We did not see any waves like this; instead, we saw similarly rapid waves, but they were horizontal instead of vertical. The claw was extended quickly to a 30-40 degree angle (as measured on photographs) and then returned to the resting position. These waves had a duration of $\sim 0.2 \mathrm{sec}$ and were often repeated at intervals of $\sim 0.5 \mathrm{sec}$, like the "vertical waves" of Australian crabs [6]; however, we did not have available the sophisticated video system of How et al. [6, 7], so the durations and frequencies reported here are estimates. Sequences of over 20 were observed. Like the vertical waves of How et al., these rapid horizontal waves (RHWs) were used primarily in agonistic interactions and were addressed primarily to crabs that were in closer proximity than crabs receiving normal waves (Figure 2(b)). However, unlike the regular waves, there were no significant differences among the groups for the RHW. They were also directed to other males more often than toward females (73\% versus $9 \%$ ), although this was biased by the presence of fewer females, as noted above. Male crabs at a distance might wave back and forth at each other, and then one would continue to approach the other, who would then direct RHWs at the intruder who might either retreat or perform RHWs in response. While retreat was the more common result, RHWs back and forth sometimes led to a "butting match," where the two crabs would push each other until one retreated (Figure 1(b)). In one case, a crab in a butting match was observed to pick up the other and toss it away. RHWs were also addressed toward nearby females, who invariably retreated. No real courtship was observed, and no female was seen to enter a male's burrow. Rather, all females retreated from the waving males.

RHWs were also occasionally directed toward members of other species on the flat, $U$. vocans and $U$. tetragonon, but only when they were in much closer proximity than the targets of intraspecific RHWs (Figure 2(b)). However, these other species ignored the RHWs; they obviously did not "speak the language."

When both kinds of waves were compared for distance (using only male-male data), the differences between wave types are more obvious (Figure 3 ). K-W one-way ANOVA for Figure $3=50.7, P<0.001$.

We have examined the two types of waves performed by a population of $U$. perplexa in Fiji. The RHWs appear comparable in speed and function to the "vertical" waves described by Crane [1] and How et al. [6] in this species in Australia. Crane [1] stated that the vertical waves were used for agonistic interactions, which appears to be the message of the RHW described here. These waves tended to be addressed to target crabs that were in closer proximity than targets 


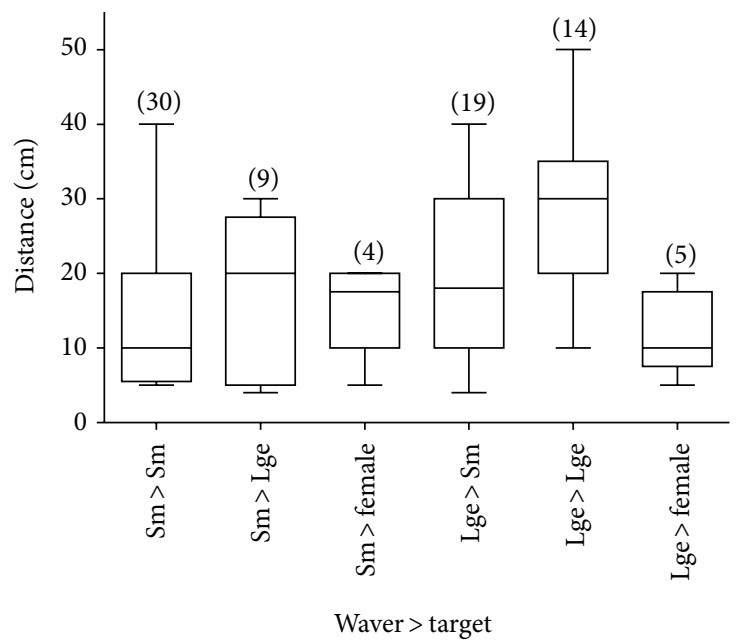

(a)

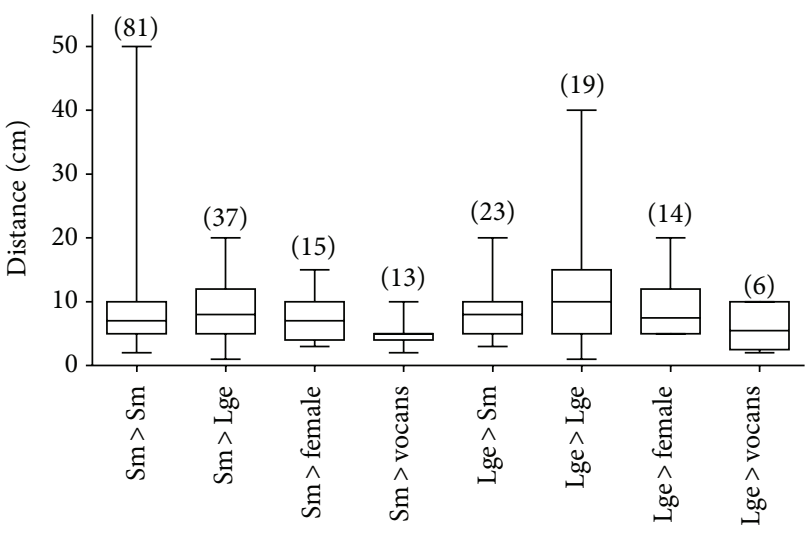

Waver $>$ target

(b)

Figure 2: Regular waves (a) and RHW (b) in relation to distance, according to target. For (a), Kruskal-Wallis statistic $=15.5, P=0.031$; data in (b) are not significantly different. Numbers of observations $(n)$ are in parentheses above graph bars.

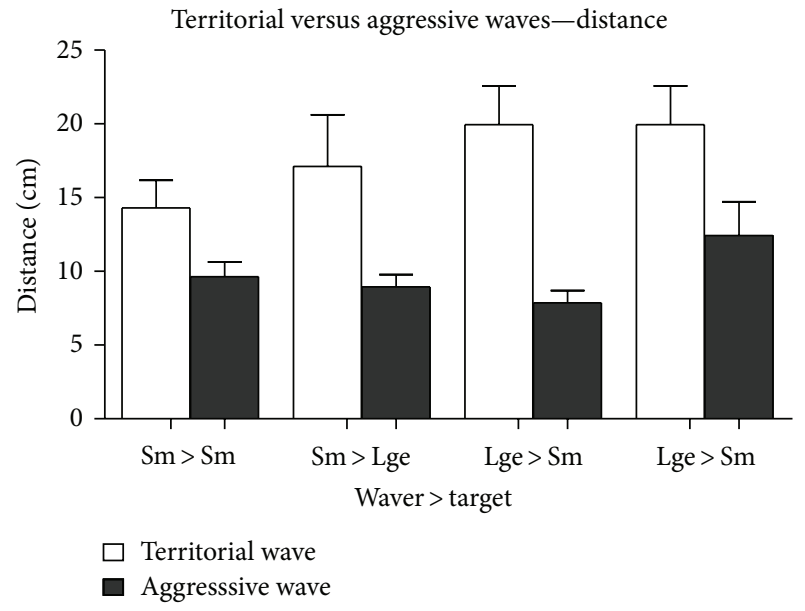

FIgURE 3: Regular versus RHW in relation to distance (males only). Kruskal-Wallis statistic $=50.7, P<0.0001$. Kruskal-Wallis one-way ANOVA $=15.4, P=0.0084$.

of "regular" waves. As females approached, males increased their intensity of waving but reduced the lateral component of the wave. It is logical that a larger, more conspicuous wave would be directed toward more distant receivers.

The rapid vertical waves of How et al. $[6,7]$ would be visible only to rather nearby individuals. The same would be true for the RHW of the Fiji crabs, which would probably be visible to a narrow range of observers that were both nearby and directly in front of the displaying crab. While the vertical waves included striking of the chela on the substrate, which might produce surface vibrations audible to other fiddler crabs, such acoustic signals do not appear to be possible with the RHW described. However, the RHW can be (and was) also used to push the other crab away. The forward direction of this Fijian variation is especially amenable to being converted into pushing.
A wave similar to the RHW was recently observed in the related U. lactea [10], who called it "lateral-flick waving" and noted that it was directed "mostly to neighbouring resident males," similar to our observations in U. perplexa.

Geographic variation in waving (regular or "lateral") by this species has previously been noted by How et al. [11] who described differences between Australian and Japanese populations of $U$. perplexa. However, those geographical differences were subtle, requiring video analysis to differentiate, whereas the difference between a rapid vertical [6] versus horizontal, as described here, is a major distinction in the nature of the wave. The horizontal wave performed in Fiji appears to convey the same aggressive/agonistic message as the vertical wave in Australia. Geographical differences in signaling behaviors could be an initial step toward speciation [12]; however, since our observed difference is not a mating behavior, its relation to speciation is not apparent.

\section{Conclusions}

A population of the lemon-clawed fiddler crab (U. perplexa) in Fiji was found to have an aggressive signal that differs from that of another well-studied population (Australian). This appears to be a regional "dialect" for this mode of communication. The territorial display is, on the other hand, consistent between these two populations.

\section{References}

[1] J. Crane, Fiddler Crabs of the World (Ocypodidae: genus Uca), Princeton University Press, New Jersey, NJ, USA, 1975.

[2] M. S. Rosenberg, "The systematics and taxonomy of fiddler crabs: a phylogeny of the genus Uca," Journal of Crustacean Biology, vol. 21, no. 3, pp. 839-859, 2001.

[3] M. Salmon, G. W. Hyatt, K. McCarthy, and J. Costlow, "Display specificity and reproductive isolation in the fiddler crabs, Uca 
panacea and U. pugilator," Zeitschrift fur Tierpsychologie, vol. 48, pp. 251-276, 1978.

[4] T. Detto, P. R. Backwell, J. M. Hemmi, and J. Zeil, "Visually mediated species and neighbour recognition in fiddler crabs (Uca mjoebergi and Uca capricornis)," Proceedings of the Royal Society B, vol. 273, no. 1594, pp. 1661-1666, 2006.

[5] Y. Nakasone and M. Murai, "Mating behavior of Uca lactea perplexa (Decapoda: Ocypodidae)," Journal of Crustacean Biology, vol. 18, no. 1, pp. 70-77, 1998.

[6] M. J. How, J. Zeil, and J. M. Hemmi, "Differences in context and function of two distinct waving displays in the fiddler crab, Uca perplexa (Decapoda: Ocypodidae)," Behavioral Ecology and Sociobiology, vol. 62, no. 1, pp. 137-148, 2007.

[7] M. J. How, J. M. Hemmi, J. Zeil, and R. Peters, "Claw waving display changes with receiver distance in fiddler crabs, Uca perplexa," Animal Behaviour, vol. 75, no. 3, pp. 1015-1022, 2008.

[8] M. Murai and P. R. Y. Backwell, "More signalling for earlier mating: conspicuous male claw waving in the fiddler crab, Uca perplexa," Animal Behaviour, vol. 70, no. 5, pp. 1093-1097, 2005.

[9] M. Murai and P. R. Y. Backwell, "A conspicuous courtship signal in the fiddler crab Uca perplexa: female choice based on display structure," Behavioral Ecology and Sociobiology, vol. 60, no. 5, pp. 736-741, 2006.

[10] D. Muramatsu, "For whom the male waves: claw-waving display of male fiddler crabs," in Proceedings of the the Crustacean Society Summer Meeting, Tokyo, September 2009, abstract [GE5].

[11] M. J. How, J. Zeil, and J. M. Hemmi, "Variability of a dynamic visual signal: the fiddler crab claw-waving display," Journal of Comparative Physiology A, vol. 195, no. 1, pp. 55-67, 2009.

[12] J. Bro-Jørgensen, "Dynamics of multiple signalling systems: animal communication in a world in flux," Trends in Ecology and Evolution, vol. 25, no. 5, pp. 292-300, 2010. 

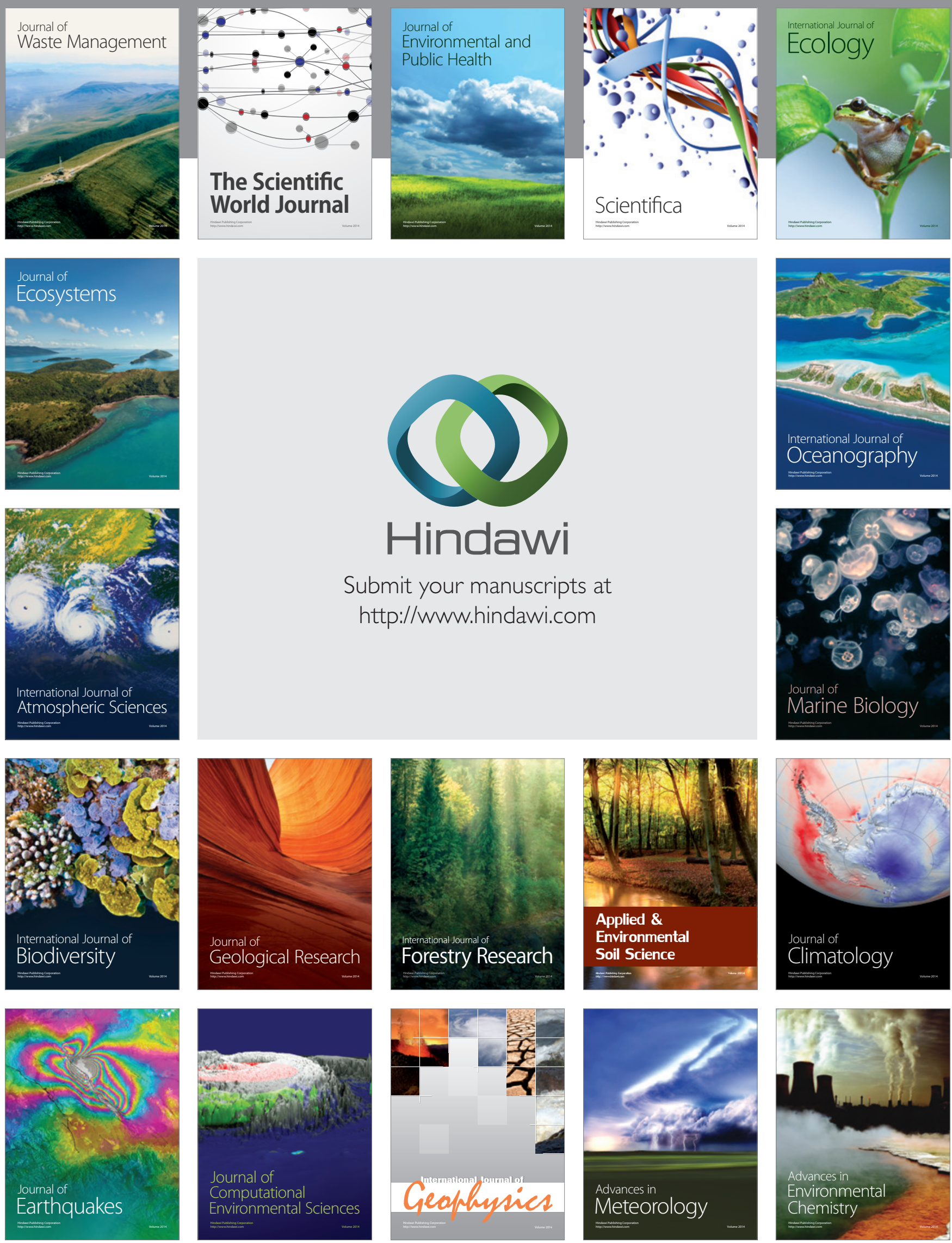